\title{
Chapter 13 \\ Integrated Interventions to Address Sex Workers' Needs and Realities: Academic and Community Insights on Incorporating Structural, Behavioural, and Biomedical Approaches
}

\author{
Sheree Schwartz, Nikita Viswasam, and Phelister Abdalla
}

\section{Introduction to Integrated, Multi-component, Multi-level Interventions}

Sex workers experience threats to their physical and mental health from varying and intersecting factors [1-4]. As described in previous chapters, stigma, human rights violations, exposure to violence, unintended pregnancy, HIV, and other STIs create complex health inequities that are less likely to be addressed through interventions focusing on one type of 'risk factor'. Recognising that individuals reside in complex environments influenced by multiple levels is thus essential for designing interventions $[5,6]$. The health outcomes of sex workers are impacted at varying levels, from individual and interpersonal factors, to community and policy factors [7]. Examples of these factors at different levels include sex workers' clients refusing to use condoms, which increases risk of acquiring HIV and other STIs; stigma and discrimination from healthcare providers hindering sex worker's engagement in health care; and physical and sexual violence by clients, partners, and law enforcement officers targeting sex workers [1, 4, 7-9]. Furthermore, laws that criminalise sex work play a critical role in reinforcing marginalisation, perpetuating stigma and undermining violence prevention efforts and access to health care [10]. The existence of these multi-level factors suggests that narrowly focused interventions addressing a single disease or issue are unlikely to succeed. Addressing multiple layers of marginalisation calls for multi-level, integrated interventions.

\footnotetext{
S. Schwartz $(\bowtie) \cdot$ N. Viswasam

Key Populations Program, Department of Epidemiology, Johns Hopkins School of Public Health, Baltimore, MD, USA

e-mail: sschwartz@jhu.edu; nviswas1@jhu.edu

P. Abdalla

Kenya Sex Workers Alliance, Nairobi, Kenya

e-mail: keswa04@gmail.com
} 
The goal of this chapter is to introduce the concepts of layered, multi-component, and multi-level interventions and explore the ways in which interventions can address sex workers' needs through a combination of structural-, behavioural-, and biomedical-level activities. Critical to this goal is recognition that intervention success will only be achieved if perspectives, priorities, and leadership by sex workers drive the approach.

To begin, we discuss types of interventions, including integrated and multicomponent interventions, as well as biomedical, behavioural, and structural approaches to interventions. An integrated health intervention is one that uses two or more approaches to address an underlying health need or problem. For example, integrated health services for cisgender female sex workers might include HIV prevention and/or treatment provision alongside provision of contraception, thus integrating family planning and HIV care. Similarly, a multi-component intervention is one that includes multiple activities as part of the overall approach. This could be an integrated approach in which sex workers receive multiple services at one location, or it could be that different components are offered at different times and different places, but all with the common goal of addressing underlying vulnerabilities or needs.

Component parts of interventions may use biomedical, behavioural, or structural approaches (Fig. 13.1). Biomedical interventions use clinical or medical approaches to address health outcomes. In the HIV field, pre-exposure prophylaxis

\section{Types of Interventions}

\begin{tabular}{|c|c|c|}
\hline Structural & Behavioral & Biomedical \\
\hline $\begin{array}{l}\text { Aim } \\
\text { Change economic, legal, } \\
\text { political, or social } \\
\text { environmental factors } \\
\text { that shape public health } \\
\text { outcomes }\end{array}$ & $\begin{array}{l}\text { Aim } \\
\text { Support changes in } \\
\text { human behavior to } \\
\text { influence health } \\
\text { outcomes }\end{array}$ & $\begin{array}{l}\text { Aim } \\
\text { Provide clinical or } \\
\text { medical approach to } \\
\text { health outcomes }\end{array}$ \\
\hline \begin{tabular}{l}
\multicolumn{1}{c}{ Example } \\
- Decriminalise sex work \\
Community \\
empowerment, such as \\
enhancing skills to \\
mobilise or engage in \\
legal advocacy \\
- Sensitivity training for law \\
enforcement
\end{tabular} & \begin{tabular}{l}
\multicolumn{1}{c}{ Example } \\
- Peer education on \\
strategies to improve \\
condom use with clients \\
and partners \\
- Self-efficacy building \\
workshops to increase \\
treatment adherence
\end{tabular} & $\begin{array}{l}\quad \text { Example } \\
\text { - PrEP program for sex } \\
\text { workers } \\
\text { - STI treatment services } \\
\text { - Post-violence response } \\
\text { medical care and } \\
\text { reporting support }\end{array}$ \\
\hline
\end{tabular}

Fig. 13.1 Structural, behavioural, and biomedical interventions 
(PrEP) to prevent HIV would be an example of a biomedical intervention to promote health among sex workers. Behavioural interventions focus on influencing or supporting changes in human behaviour. Using the HIV prevention example, behavioural interventions may support sex workers to continue on PrEP, often through motivating individuals and creating strategies or incentives to engage in positive health-seeking behaviours. Structural interventions attempt to alter the underlying context that shapes public health outcomes-through changing the economic, political, legal, or social environment in which individuals operate. Examples of structural interventions might be legal reform or policy guidelines which decriminalise sex work, provision of violence prevention interventions for sex workers which target police as potential perpetrators and violence mitigators, or empowerment programmes to build social support, resilience, and autonomy among sex workers. Addressing violence and incorporating referral into programming, addressing trauma and ensuring continued access to treatment and prevention during times of arrest or detainment are also essential. Multi-component interventions, which integrate elements across these three intervention types, are increasingly recognised as important to improving health outcomes, as each one attempts to address different needs or barriers to positive health outcomes.

Interventions addressing a combination of biomedical, behavioural, and structural approaches are often multi-level interventions. Multi-level interventions seek to address needs or barriers to positive health outcomes which may stem from various sources - namely barriers at the individual level, social and network level, the community level, and the legal/public policy level. These approaches recognise that individuals are not entirely independent beings, but rather are embedded and interact within environments that shape and influence their life outcomes. Thus, multi-level interventions are designed to influence a variety of actors-not just sex workers. Healthcare workers, police officers, and policymakers are all potential actors engaged in various types of multi-level interventions, in addition to sex workers and their clients.

In summary, an integrated, multi-component intervention combines more than one intervention activity, targeting two or more of the three approaches (biomedical, behavioural, and/or structural). Not all integrated or multi-component interventions will include components across these areas. Typically, interventions spanning all three areas will also be multi-level in nature, as they tend to be targeting different barriers or facilitators to health. Community perspectives from The Kenya Sex Workers Alliance (KESWA) (Boxes 13.1 and 13.2) highlight why integrated, multicomponent interventions including structural interventions are necessary for improved health outcomes among sex workers, even when biomedical health services for sex workers are available [11]. 


\section{Box 13.1 Perspectives of the Kenya Sex Workers Alliance (KESWA) on the Impact of the Structural Environment on Violence Against Sex Workers in Kenya}

The legal environment in Kenya is comprised of laws and policies that provide a framework to address sexual and gender-based violence. However, the existence of punitive criminal provisions hinders effectiveness of interventions, particularly for key populations such as sex workers. These provisions allow law enforcement officers to abuse sex workers with impunity-for example, targeting sex workers and extorting them for sex in exchange for their freedom when they are unable to pay a bribe. Data from a KESWA survey suggest that sexual exploitation involving police officers is largely targeted at female sex workers with $8.4 \%$ of sex workers in Kenya reporting demand for unprotected sex to secure their release. Fifty-two percent of sex workers consider law enforcement agents to be the greatest threat to their safety and security. This contributes to mistrust and general fear of law enforcement agents, discouraging reporting of violence with only $34.3 \%$ having reported violence that they had experienced. Despite $50.6 \%$ of sex workers having been part of forums organised for sex workers, legal awareness and human rights empowerment is not adequately covered.

The policy environment has played a major role in strengthening access to medical interventions for sex workers (e.g. HIV care), but has had less of an effect on other services required to address violence including psychosocial services, rehabilitation and reintegration, victim protection and legal support. These findings were reported by KESWA, the collective of Kenyan sex worker-led organisations in Silenced by Law: the Impact of the Legal Environment on Health, Safety and Protection in Relation to Sex Work related Violence in Kenya exploring six critical areas: legal reform, enhancing access to justice, legal awareness for sex workers, enhancing safety and security, enhancing health and social services and research. This report highlights the need for integrated interventions including structural, behavioural, and biomedical approaches to violence, sexual and reproductive health, and HIV/ STIs care to effectively improve sex worker health and well-being.

\section{Evaluation of Integrated Interventions}

Evaluating interventions is necessary to determine the impact that services have on sex workers' health outcomes and quality of life. Evaluation may be particularly complicated when interventions are integrated and multi-component. Did each component of the intervention work independently from the other, or did the intervention components in combination produce a different effect than what might have been achieved in the absence of the other intervention? For example, if an intervention addresses workplace safety, enhanced negotiation skills among sex workers, 


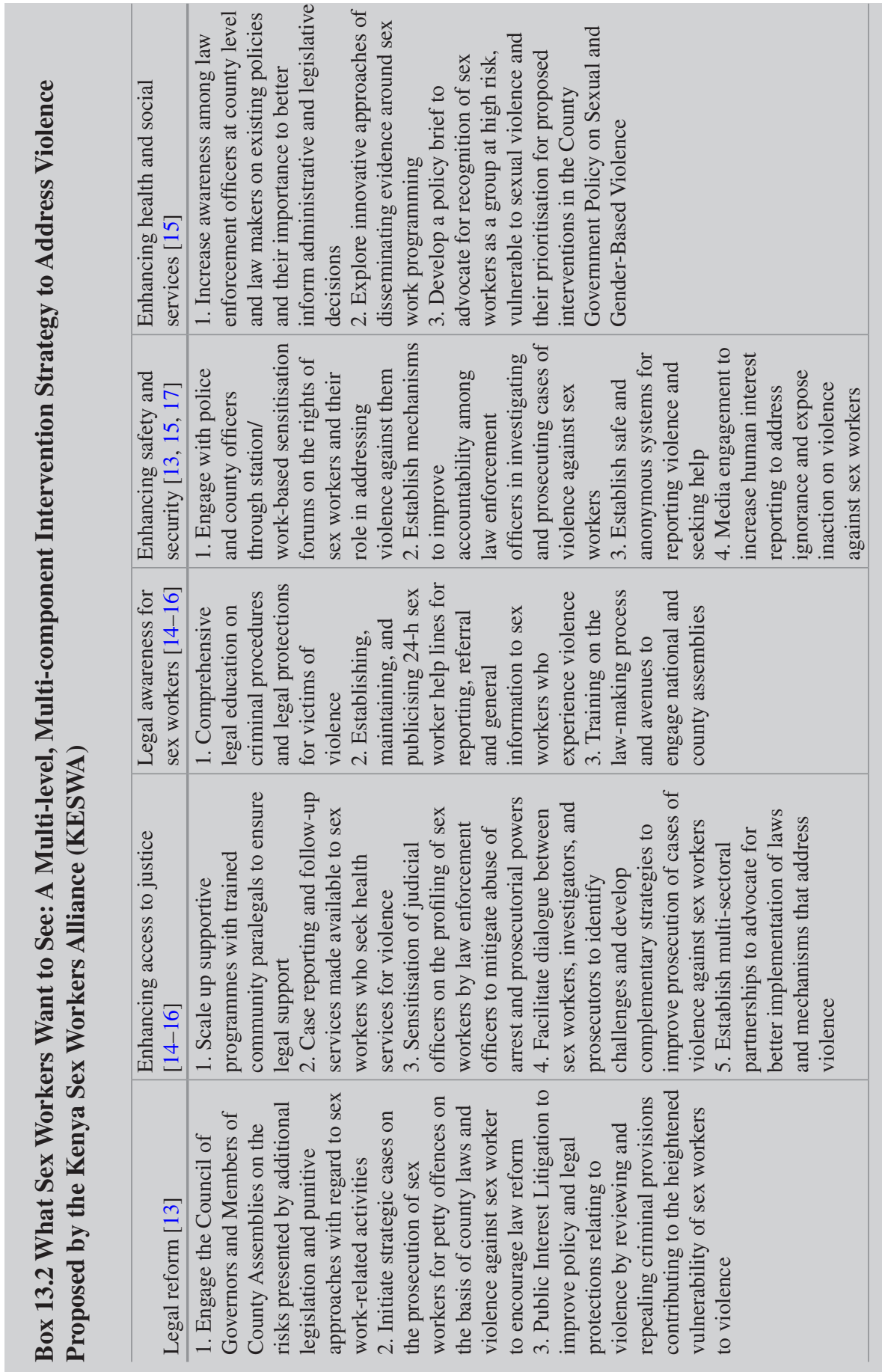


and provision of free condoms and lubricants, do these interventions each work better when the other one is co-occurring? Similarly, were all components necessary for an effect or could the intervention have been sufficiently successful with a more minimal package? If the intervention did not work, might it have it succeeded if there had been an additional component added?

\section{Specifying the Intervention and Outcomes}

Given the complexities described above, the first piece of evaluating any intervention - and particularly integrated, multi-component interventions-is intervention specification [12]. What exactly is included in each component of the intervention? Who is delivering and who is receiving the intervention? When will it be delivered, where, how much, and for how long? Are the components envisioned to operate independently or is there a specified sequence of the components? Clear specification is necessary to facilitate reproducibility of results, compare the effectiveness of intervention components, and to evaluate the extent to which effect or lack of effect is due to how well the intervention was implemented. For example, did the intervention fail because it did not work, or because parts of it were not implemented fully or correctly as specified?

Clearly outlining activity details and adaptations will ensure that successful achievements can be tried in other settings. Further, clear articulation of actors and steps should reveal the centrality of the sex work community to intervention design and implementation. Are sex worker priorities represented in the listed activities? Are sex workers taking on leadership activities in formative phases to design interventions? Are they implementing components of the interventions? For each of the components-who was the source of the intervention-were components determined by external stakeholders or do they emanate from sex workers themselves?

Community perspectives from KESWA (Box 13.2) highlight various components of a sex worker-led multi-level, multi-component intervention that is currently being implemented to address violence faced by sex workers in Kenya. Approaches include law reform [13], enhancing access to justice [14-16], legal awareness for sex workers [14-16], enhancing safety and security [13, 15, 17], and enhancing health and social services [15]. Future evaluation of the effectiveness of this multi-component approach in Kenya at reducing threats to health, stigma, and discrimination experienced among sex workers will be critical.

Finally, evaluations must consider a broad array of health outcomes to monitor success. Outcomes must include those most prioritised by the sex worker community, such as violence and fear of violence, and other human rights abuses. Focusing only on HIV or STI-related outcomes is insufficient as it ignores the broader context of change that is necessary to support health. Measurement of stigma, violence, human rights violations, and behaviours of healthcare providers, police, and clients will provide a clearer picture of the mechanisms of change. Additionally, measuring implementation outcomes such as intervention acceptability, adoption, appropriate- 
ness, feasibility, and fidelity of implementation as described by Proctor et al. can further ensure that intervention components are aligned to the needs and priorities of the sex work community [18].

\section{Challenges in Evaluation of Multi-component, Multi-level Interventions Among Sex Workers}

Evaluation approaches which allow for comparisons across time periods and exposure to interventions are important to promote evidence-based approaches, but this type of evidence is rarely gathered for sex worker interventions [19]. Communityled monitoring of intervention implementation and success should be incorporated and can ensure community-led insights are guiding implementation. Data reported are often cross-sectional (collected at one point in time) and thus provide little understanding of changes over time, which are typically needed to document impact. Programmatic data, while critical to monitor implementation success, often lack control groups for comparison-as everyone in the programme is typically offered the interventions. Thus, changes in outcomes over time may be attributable to the interventions, or they may have resulted from other co-occurring initiatives. Further, randomised controlled trials-in which one group is randomly allocated to receive an intervention and another receives the standard of care or an alternative intervention-have less frequently been implemented among sex workers. While randomised trials are critical for establishing the efficacy of many biomedical products, they are often less appropriate for understanding real-world implementation and, if implemented (such as a comparison of two strategies to implement the same evidence-based intervention), need to ensure equipoise. As such, intervention designs and evaluation will need to rely on more creative and observational methods, including causal inference approaches to account for selective outcome ascertainment or to assess outcomes right before and after a policy was implemented, pre- and post-designs in which areas that were not implementing the intervention share pre- and post-data for comparison, as well as data reporting on the implementation process and outcomes [20,21].

Finally, evaluation of multi-component, multi-level interventions pose unique challenges-including how to measure the impact of individual components when multiple components are offered, and evaluation of the need for each component, as each additional component will have additional costs and complexities. Similarly, structural interventions are often implemented at a macro-level (e.g. a change of policy) and thus variation of the exposure within an area is not even feasible [20].

These complexities should not discourage evaluation of interventions, but rather can be used as a platform to ensure meaningful engagement between sex work communities, implementers, and researchers to explore opportunities to evaluate success that are both robust and supported by the sex worker community. There are opportunities for more rigorous design-including use of quasi-experimental 
designs [20], as well as the potential for randomisation of smaller component parts or the way that the intervention is delivered (e.g. by sex worker peers or by healthcare providers). Incorporation of sex worker preferences into the design and evaluation plans and activities should be prioritised from the outset and can be achieved through both quantitative and qualitative approaches [22], as well as community-led monitoring.

\section{Evidence of Impact of Integrated, Multi-component Interventions}

There are single component sex work interventions with varying degrees of effectiveness to promote health outcomes. Interventions include condom and lubricant distribution, legal reform, and other structural interventions with police to reduce condom confiscation, discrimination, and violence perpetration, as well as advocacy measures to support access to justice for sex workers experiencing violence $[15,23,24]$. Direct health service delivery is the most common strategy applied, including screening and treatment programmes for sexually transmitted infections, voluntary HIV testing programmes, antiretroviral therapy provision, and comprehensive family planning services. However, there is growing recognition of the need to layer services with community mobilisation efforts to build advocacy and social cohesion among sex workers, interventions to prevent gender-based violence, and community empowerment efforts to address unsafe work environments, violence, structural discrimination, and address education needs [25]. Furthermore, laws criminalising sex workers, clients, and third parties have been demonstrated to negatively impact health outcomes $[24,26]$. Thus, while single interventions may result in some important improvements and may be easier to assess, they are unlikely to achieve sustainable population-level impact or to sufficiently address the multipronged factors and health concerns faced by sex workers. Thus, we review the evidence of integrated, multi-component interventions on health outcomes.

Of note, there are many sex worker-led interventions globally that target structural reform, advocate for sex worker protections, and promote and implement service delivery. Interventions determined by the community to have benefit are often continued and de-implemented where benefit is not observed; however, external dissemination of evaluation efforts is often lacking, limiting the creation of a robust evidence base. Funding has prioritised the implementation and evaluation of primarily biomedical and behavioural intervention approaches, and many of the structural initiatives remain unevaluated. As such, structural approaches remain under-represented in evidence syntheses, including the evidence presented in the following sub-sections. Further efforts to evaluate and capture lessons learned from sex worker-led and community-based interventions, especially addressing structural factors, therefore remain needed to fully capture impacts on outcomes and should be supported through funding and skills transfer initiatives to build capacity 
in evaluation, dissemination, and communication. Further financial support for sex worker-led organisations to drive evaluations of their interventions is critical, and consideration of potential partnerships with advocates in the research community to support training in evaluation methods may represent an important opportunity for collaborative work. Frequently, the model is for researchers to approach sex workers with ideas, but this paradigm can be turned upside down and would benefit both the sex worker and research communities.

\section{HIV and STIS}

For many years, condom provision and promotion were the primary methods of HIV and STI prevention programmes. In the 1990s, the 100\% Condom Campaign in Thailand combined condom provision, mass marketing, and policies to promote condom use in sex work establishments to reduce HIV incidence and prevalence in Thailand [27]. Although this is an example of a structural intervention that achieved prevention success, the programme reinforced coercive environments rather than promoting empowerment, was not designed or led by sex workers, and is an example of top-down approaches to reform which have been widely condemned by the sex work community [28].

Increasingly, multi-component, multi-level strategies are moving beyond condom provision and promotion alone as prevention strategies. A systematic review of combination prevention interventions implemented in sub-Saharan Africa published from 2000 to mid-2016 found that, generally, multi-level interventions mediated by peer educators increased condom use [29]. Evidence of impact on new HIV and STI infections, however, was more mixed. Large-scale HIV and STI prevention programmes have demonstrated substantial decreases in both HIV and STI prevalence over time in Benin, Cote d'Ivoire, and Burkina Faso [30-33]. However, none of these studies were randomised and may potentially reflect underlying secular trends over time rather than an effect attributable to the interventions implemented. Among eight randomised trials during this time, only the Kenyan trial focused on peer support and organisation empowerment. It also achieved STI prevention as demonstrated by declines in STIs, though not on HIV incidence [34, 35]. Studies evaluating isolated interventions or comparing multi-component to isolated interventions reinforce the need to combine more than one type of approach [36]. A randomised controlled trial in Madagascar among 1000 female sex workers found that peer condom promotion alone was not effective but, when combined with individual counselling, it reduced STIs by $30 \%$ after 6 months [37]. Outside of the African continent, multi-level interventions, which included strategies to modify environmental conditions and support collective action implemented in Brazil and the Dominican Republic, have increased social cohesion and condom use, thus resulting in declines in STIs $[38,39]$, though experimental designs and demonstrated impact on HIV incidence are still needed. 
The Avahan study in India was the largest programme implemented to date to apply a combination prevention approach to reduce HIV incidence. It is notable as it included both individual-level, community-level and structural components. Peer outreach, counselling, condoms, needle and syringe exchange, clinic services, community mobilisation, and advocacy activities for sex workers and clients was implemented in six states. Overall, results from repeated surveys and modelling indicated that HIV prevalence significantly declined in four out of the six states implementing the intervention [19, 40]. Although the evaluation approach (mathematical modelling) has been considered controversial, an estimated 202,000 infections were averted during the study [40-42].

Community-based research approaches-including community empowerment interventions that seek to change social environments alongside condom provision and promotion and biomedical solutions-remain crucial as the importance of addressing structural challenges to prevention and care are increasingly recognised. A comprehensive review and meta-analysis of community empowerment analyses spanning eight projects demonstrated a positive impact on HIV and STI prevention associated with community empowerment approaches [43]. However, weak study designs were pervasive, geographic representation was limited, and few male or transgender sex workers were included in the studies. The authors concluded that there was a need to leverage empowerment initiatives as part of more comprehensive combination intervention.

More evidence of impact of multi-component interventions to increase PrEP uptake, antiretroviral therapy (ART) coverage, and viral suppression among sex workers living with HIV is urgently needed. There is evidence that structural determinants including mobility, incarceration, and punitive environments negatively impact ART use among sex workers [44]. Evidence from the community-based SAPPH-IRe sex work programme in Zimbabwe-including peer-led empowerment and mobilisation, and concurrent ART scale-up_resulted in increased ART coverage and viral suppression over time among female sex workers. These results were also seen in the broader population. Modelling suggests the importance of these interventions in altering the epidemic curve [45]. Yet the SAPPH-IRe combination prevention trial — including community mobilisation, HIV testing, ART, and PrEPdid not show significant reduction in HIV infections or viral suppression despite an uptake of services, reminding us again that individual-level impacts do not necessarily result in population-level effectiveness [46].

Evidence of the impact of legal reform on HIV outcomes remains limited. There is now substantial evidence pointing to the HIV-associated risks related to criminalised legal environments for sex work [10, 47, 48]. Modelling studies suggest that decriminalisation of sex work would have the biggest impact on reducing HIV incidence among sex workers, yet lack of policy changes limit the real-world evaluation of this intervention [7, 23]. 


\section{Sexual and Reproductive Health}

Outside of HIV prevention and HIV/STI screening and treatment, the evidence base for integrated, multi-component sexual and reproductive health (SRH) interventions remains limited. There is a growing body of work documenting the vast unmet needs among sex workers for contraception, safe termination of pregnancy services, safer conception care and initiatives to prevent or address sexual violence $[49,50]$. Yet global and region-specific systematic reviews have found that multi-component interventions with female sex workers pertaining to family planning, cervical cancer screening or sexual violence have been documented infrequently, and where evidence exists, it is limited largely to reports of service utilisation, rather than intervention effectiveness [51]. Differentiated care models which incorporate broader reproductive health choices including safer conception and termination of pregnancy interventions for female sex workers have rarely been implemented, and lack evaluation thereof. Globally, there is limited actual evidence for how to effectively integrate reproductive health and family planning services into sex worker programmes [52]. While undoubtedly many sex worker programmes are offering integrated, multi-component services, this lack of data limits the evidence base and results in questions regarding implementation effectiveness and efficiencies.

The limited existing data demonstrate the need for more comprehensive multicomponent interventions while indicating the challenges faced to delivering high quality integrated sexual and reproductive health care to female sex workers. In Cambodia, the SAHACOM programme used a multi-component package which included HIV/STI and reproductive health integration, as well as economic and behavioural empowerment approaches among women engaged in entertainment and sex work spaces. Results suggested an increase in contraception uptake and decrease in abortions and STIs, though more rigorous study designs of similar programmes including a comparator group are needed [53]. A separate study in Cambodia at a clinic frequented by female sex workers found no effect of integrating family planning services into facility-based HIV care [54]. In Madagascar, an RCT focused on peer education alongside clinic-based counselling on condom use found that in the absence of contraception integration, rates of unintended pregnancies were high, as condom use varies across partner types [55]. A study in South Africa, Mozambique and Kenya found that more comprehensive efforts to integrate multi-level and multi-component comprehensive sexual and reproductive health services resulted in increased uptake of sexual and reproductive health services [56]. Future efforts to replicate successful designs and incorporate control groups and long-term effectiveness outcomes remain necessary.

Finally, it should be noted that sexual and reproductive health services are relevant to male and transgender sex workers, but data documenting their reproductive health needs outside of STI treatment and condom/lubricant promotion are limited. Interventions to address screening for anal cancer, for example, are few, and more attention is warranted in this space [57-59]. 


\section{Violence and Human Rights Violations}

Human rights violations against sex workers have been documented globally, including physical and sexual violence from police, clients, and partners, and institutional discrimination in accessing health care, welfare services, and the criminal justice system [60-62]. Sex worker-led organisations have mobilised to implement human rights affirming strategies in this context [63, 64]. Crago profiled sex workerled movements addressing human rights violations globally, such as South African National Sex Workers' Network, Sisonke, which has led legal advice, crisis counselling and advocacy for sex workers as well as alongside the South African Sex Worker Education and Advocacy Taskforce (SWEAT), challenging the state's criminalisation of sex work, arbitrary unlawful arrests by police and harassment of sex workers in court. Their efforts influenced the South African government's recommendations for the reform of laws criminalising sex work in order to reduce discrimination and improve harm reduction activities among sex workers as part of an HIV prevention strategy [64]. However, a limited number of public health interventions have addressed violence among sex workers, primarily seen in the context of HIV outcomes [65-67]. Even fewer are designed as integrated multi-level interventions with activities targeting violence prevention, response, and/or other human rights violations. Examples of combination interventions addressing violence and human rights violations, however, are available from India [14-16], Kenya [17], and Mongolia [67], where activities focused on violence prevention, response, and/or police treatment of sex workers, involving capacity building around violence response mechanisms for health service organisations, training of police personnel, and individual-level skill-building for sex workers.

In India, a provincial programme by the Karnataka Health Promotion Trust, part of the larger national Avahan AIDS Initiative, took a structural and behavioural approach to addressing violence, partnering with district police heads and sex workers to train police officers in HIV/AIDS, sex work, and the law [14-16]. Furthermore, sex workers were involved in community mobilisation, skills-building activities, and legal empowerment workshops along with 24-h crisis management response teams to address reported incidents of violence and advocates to assist in the event of wrongful arrest. A similar programme in Andhra Pradesh included the same strategies as part of a community advocacy system, along with forming community action groups (CAG) [13]. Through the Karnataka initiative nearly all districts saw reductions in their violence reports. Sex workers with a longer duration of exposure to the programme were even less likely to report experiencing violence. Continued programme activities also found reduced rates of both police arrest among sex workers and arrests as part of arbitrary police raids. In Andhra Pradesh, the annual programme behavioural tracking survey found that in areas with active CAGs, the police were more likely to explain their reasons for arrest. Sex workers in areas with active CAGs reported a perception of fairer treatment by police compared to the year before. These programmes took structural and behavioural approaches to 
addressing community-level barriers through police training and mobilisation, and individual-level barriers through legal empowerment and skill-building.

In Mongolia, a randomised controlled trial was conducted examining the effect of a combination HIV sexual risk reduction and microsavings intervention on violence from clients of sex workers [67]. Its behavioural component, the HIV sexual risk reduction intervention, involved skills-building sessions around identifying safety risks, negotiating safe sex, and avoiding unsafe situations. The structural component was a microsavings intervention involving a matched-savings programme at partnering banks and training on financial literacy, business development, and vocational mentorship. This trial found significant reductions in reports of recent client violence in both the enhanced intervention group (behavioural + structural interventions) and standard groups (behavioural intervention only), though participation in the microsavings structural intervention did not further decrease exposure to violence from clients beyond the behavioural intervention alone.

In Kenya, the National Key Populations Programme took a multi-level approach to violence response. Adopting strategies as part of the National Guidelines for HIV/STI Programming for key populations, the Programme conducted trainings on violence and key population rights with implementing partner organisations. These, in turn, conducted educational activities around violence, rights, and reporting for both key population members and clinical and outreach service staff [17]. Some implementers also developed 24-h response teams involving peer educators and peer paralegals linked to clinicians and advocacy officials to assist participants disclosing violence and ensuring their direct delivery or referral to post-violence services. Annual programme data between 2013 and 2017 revealed an increase in the number of sex workers reached.

Along with the public health interventions described above, KESWA has proposed creation of a multi-level multi-component intervention addressing the legal and structural barriers preventing those who experience violence from access to justice (Community Case Study Part II). Some such interventions have been tested and cited in public health intervention literature. These strategies-grounded in the experiences of, and advocacy by, sex workers to address the legal environmentrequire further implementation and incorporation into multi-level public health interventions to build the evidence base around layered activities that increase the impact of interventions improving the health and well-being of sex workers.

\section{Mental Health and Drug and Alcohol Use}

In addition to violence, poor mental health outcomes, drug and alcohol use, and their intersections with sex work have been shown to affect engagement in health care and preventative behaviours, including protected sex to reduce HIV risk [60, 68 , 69]. While HIV prevention and care programmes often include counselling components that provide referral to mental health and psychosocial services, there 
is little evidence, however, of integrated, multi-component interventions that focus on addressing the mental health of sex workers. Some interventions involving harm reduction or substance use reduction have been documented [65, 70, 71], including limited multi-component interventions addressing substance use-one provided to sex workers using amphetamine-type stimulants (ATS), one addressing alcohol use, and another to sex workers using injection or non-injection drugs.

In Cambodia, a conditional cash transfer intervention was combined with cognitive-behavioural group aftercare sessions where participants who used ATS were supported in ATS harm reduction, self-efficacy, and skills building [72]. Evidence around the effectiveness of this intervention has not been released. In Mexico, varying combinations of interactive and didactic sexual risk reduction and injection risk reduction interventions were delivered to HIV-negative FSW in a randomised trial in Tijuana and Juarez. Results indicated declines in needle-sharing, ranging from $71 \%$ to $95 \%$ across study sites and intervention types [71]. The factorial design provided evidence that combining community and individual-level interventions was more effective. Further, more distal health impacts including reductions of HIV/STI incidence after 12 months were achieved in multi-exposure arms, including interactive sexual risk reduction components vs. didactic components.

Project Nova is a combination HIV prevention and microfinance intervention designed for women who engage in sex work and drug use in Kazakhstan [73]. This included an HIV risk reduction component and a microfinance component. HIV risk reduction activities included knowledge and skills-building in sexual and drug use risk reduction, including safety planning, and facilitators gave referrals to harm reduction and social programmes along with other medical and social assistance. The microfinance components involved financial literacy training and vocational training. A matched-savings programme was added to build self-efficacy and job skills, with the goal of further reducing sexual and injection drug use behaviours. Outcomes for this intervention have not been released.

\section{Evidence Gaps}

\section{Summarising Gaps in the Evidence}

There are several gaps in the evidence available. First, the evidence-base is overwhelmingly driven by researchers, and, moving forward, there remains an urgent need for additional sex worker-led and sex worker-academic collaborative research. Sex worker-led programming is taking place in many settings, and there is a critical need for this evidence to be rigorously evaluated and disseminated. Participatory approaches that meaningfully engage the sex worker community across all stages of the research process are especially needed, in order to ensure intervention relevance and guide the study design and evaluation to define what successful outcomes will look like and how this may be ethically assessed. Secondly, very few data are avail- 
able from studies including male and transgender sex workers, and where they have been included, disaggregated results with adequate sample sizes are rarely available. Thirdly, multi-component strategies including the full range of prevention options are needed, as well as further data on how to improve treatment outcomes for sex workers living with HIV. Further, each of the non-HIV-related health outcomes reviewed lacked a substantive evidence base. Evidence of effective, multicomponent strategies to improve reproductive health and mental health outcomes were particularly scarce. Where data of successful interventions are available, attribution of effect to intervention components was rarely possible. Finally, real-world evidence of the impact of legal reform is needed, but this first requires reform to occur.

\section{Addressing Gaps in Empiric Evidence Through Insights from Mathematical Modelling}

Mathematical modelling of intervention effectiveness and combinations of interventions can provide insights into the potential for interventions-alone or in combination-to achieve impact. In assessments of interventions among sex workers in the context of country-level HIV epidemics, modelling has been used to estimate cost-effectiveness of intervention coverage through the intervention impact on disability-adjusted life years [74, 75], as well as the impact of varying levels of intervention coverage on HIV infections averted in the sex worker community and the overall population [4, 76-78]. These include both prevention interventions, such as a PrEP [77], sexual risk reduction approaches including condom provision and improved STI treatment coverage among sex workers and clients [78], and interventions addressing ART access [76].

Fewer modelling studies have examined scenarios comparing multi-level combinations of interventions [79-81]. One important example of a multi-level, multicomponent analysis by Wirtz and colleagues used the Goals model projection to model scenarios scaling up comprehensive community-empowerment-based HIV prevention interventions and expanded ART coverage in four countries [80]. In Kenya and Brazil, scaling the empowerment intervention among female sex workers up to $65 \%$ coverage could reduce incident HIV infections by $10-12 \%$ over a 5 -year period. However, a scenario combining empowerment interventions with expanded ART coverage and equitable access to ART in the same period resulted in a $33-40 \%$ reduction in incident HIV infections among female sex workers. Separately, the Goals model also estimated that reducing violence alone against FSWs in Kenya from 32\% to 2\% resulted in a $27 \%$ reduction in incident HIV infections over 5 years [81].

These modelled data from Kenya and Brazil, alongside the aforementioned modelling study around the potential prevention impact of sex work decriminalisation, demonstrate the potential for structural interventions. They particularly highlight 
that integrated, multi-component interventions with structural components have a significant impact on the HIV epidemic [7, 80]. Still, empiric data which account for the messiness of real-world implementation and human behaviour are needed.

\section{Challenges with Evidence Creation}

In the section above, we have noted substantial gaps in the evidence for integrated, multi-component interventions for sex workers. Challenges to the creation of a robust base of evidence are multiple; these include: limited community-led monitoring, meaningful academic-sex worker partnerships, ethically and scientifically appropriate comparison groups, teasing out of the individual and joint effectiveness of the different intervention components, and incomplete detailing of intervention components. Furthermore, while intervention approaches grounded in community empowerment have demonstrated impact on health engagement and outcomes, including through reductions in HIV and other STIs [43], this impact is nevertheless still limited by structural barriers to implementation, including criminalisation of sex work, violence, multiple forms of stigma and discrimination. UNAIDS has crucially noted all of these as the foremost barriers to sex workers' rights to health and well-being [82]. These challenges and suggested paths forward are described below.

From a research perspective, approaches are often led by academics with insufficient guidance and lack of design leadership from sex work communities. Further, the priorities of sex workers and clients may often fall outside of the scope of traditional funding sources, particularly the large-scale structural interventions which often require substantial investment. Conversely, sex worker-led programmes are commonly integrated, multi-component interventions; however, insecure funding streams for sex worker-led organisations often preclude cohort data from these interventions, and comparator groups are often not available. Trend analyses over time are important, but typically do not account for secular trends. For example, increased uptake of antiretroviral therapy among sex workers living with HIV has been documented in many settings, but these trends coincide with massive countrylevel scale-up of ART generally. Scientific rigour could be increased by the use of quasi-experimental designs including comparison groups or stepped-wedge designs, which incrementally (and randomly) roll-out interventions across areas [20]. Furthermore, policy changes implemented at the macro-level typically cannot be randomised. More rigorous approaches such as time-series analyses, instrumental variable analysis and regression discontinuity may be useful for evaluating these questions. These tools, however, have only infrequently been applied to sex workrelated interventions [83-85]. Qualitative data collection and evaluations of implementation are also needed to triangulate available information and increase understanding of why interventions succeed or fail and how they may be further adapted to a given context.

Secondly, multi-component interventions, by definition, have multiple components. Determining the comparative effectiveness of intervention components and 
identifying which particular components contribute to success is often challenging. Were each of the pieces implemented as planned? Do the components have an additive effect, such that if you removed one component you may get less of a result, but still have impact, or is there a synergistic effect such that multiple components are needed to observe or magnify the effect (e.g. the sum is greater than the individual parts)? Similarly, if one component unexpectedly has a negative effect, the multicomponent intervention impact may appear to be null, when in reality parts of the intervention worked well while other components were harmful. Designs testing combinations of interventions may be impractical; however, incremental testing which iteratively assesses components-and ideally is sex worker driven-may help to optimise multi-component packages [86].

Finally, many published reports and papers of integrated, multi-component interventions lack clear specification of intervention details. A general idea of the intervention may be available, but clarity regarding specific intervention components and implementation details are often missing. Thus, replication of success may be difficult across settings, and even within national programmes interpretation and implementation of interventions may be uneven. Specification of details, such as the actor delivering the intervention (e.g. peer, counsellor, nurse), the dosage of the intervention components to be received, the duration of interventions, and the presiding context is critical to understanding its effectiveness. Interventions will inevitably need to be adapted to local contexts; however, clear specification can help to provide an initial evidence-based approach from which adaptation can occur. It should also be recognised that different individuals are likely to require different levels of intervention intensity. It may be efficient financially to tailor approaches if, for example, not all sex workers may benefit from every component of the intervention package. However, the logistics of tailored implementation and perceptions of unfairness among sex workers may pose challenges. These are all questions that must be answered scientifically and through sex work community leadership when designing effective integrated, multi-component interventions.

\section{Conclusion}

There is a growing understanding that addressing the multi-level barriers to improved health outcomes for sex workers will require integrated, multi-component responses. Programmes to address the needs of sex workers increasingly employ multi-pronged strategies. Evidence of the effectiveness of these approaches has not yet caught up. Structural interventions, particularly, are needed to address the environmental conditions within which individuals live, work, and experience threats to health and well-being. Successful efforts will require a human rights-based approach that focuses on individual needs, assets, and opportunities, and addresses contextual barriers. Access to health care and a life free from violence and discrimination are tenets that must underpin each intervention component. This goal will increasingly 
be realised if and when programmes are driven by sex workers with adequate funding and support from external partners.

Partnerships between community and academic researchers may help to ensure that standards of relevance, ethics, and rigour are met and are evaluated through a mixture of methods which infuse the voices and experiences of sex workers into the design, evaluation, and interpretation of sex work intervention research. In a time of increasingly limited resources, determining the right combination of strategies to achieve benefit is needed. Real-world conditions expose many implementation challenges that may not be immediately apparent when approaches are being conceptualised. Determining the optimal approach, especially for those most marginalised, will necessitate strong engagement and leadership from the sex work community, careful measurement and evaluation, and funding prioritisation for community-led monitoring.

\section{References}

1. Fitzgerald-Husek A, Van Wert MJ, Ewing WF, Grosso AL, Holland CE, Katterl R, et al. Measuring stigma affecting sex workers (SW) and men who have sex with men (MSM): a systematic review. PLoS One. 2017;12(11):e0188393.

2. Baral S, Beyrer C, Muessig K, Poteat T, Wirtz AL, Decker MR, et al. Burden of HIV among female sex workers in low-income and middle-income countries: a systematic review and meta-analysis. Lancet Infect Dis. 2012;12(7):538-49.

3. Oldenburg CE, Perez-Brumer AG, Reisner SL, Mattie J, Barnighausen T, Mayer KH, et al. Global burden of HIV among men who engage in transactional sex: a systematic review and meta-analysis. PLoS One. 2014;9(7):e103549.

4. Deering KN, Amin A, Shoveller J, Nesbitt A, Garcia-Moreno C, Duff P, et al. A systematic review of the correlates of violence against sex workers. Am J Public Health. 2014;104(5):e42-54.

5. Boily MC, Shannon K. Criminal law, sex work, HIV: need for multi-level research. Lancet HIV. 2017;4(3):e98-e9.

6. Schwartz SR, Rao A, Rucinski KB, Lyons C, Viswasam N, Comins CA, et al. HIV-related implementation research for key populations: designing for individuals, evaluating across populations, and integrating context. J Acquir Immune Defic Syndr. 2019;82(Suppl 3):S206-S16.

7. Shannon K, Strathdee SA, Goldenberg SM, Duff P, Mwangi P, Rusakova M, et al. Global epidemiology of HIV among female sex workers: influence of structural determinants. Lancet. 2015;385(9962):55-71.

8. Decker MR, Crago AL, Chu SK, Sherman SG, Seshu MS, Buthelezi K, et al. Human rights violations against sex workers: burden and effect on HIV. Lancet. 2015;385(9963):186-99.

9. Dourado I, Guimaraes MDC, Damacena GN, Magno L, de Souza Junior PRB, Szwarcwald CL, et al. Sex work stigma and non-disclosure to health care providers: data from a large RDS study among FSW in Brazil. BMC Int Health Hum Rights. 2019;19(1):8.

10. Reeves A, Steele S, Stuckler D, McKee M, Amato-Gauci A, Semenza JC. National sex work policy and HIV prevalence among sex workers: an ecological regression analysis of 27 European countries. Lancet HIV. 2017;4(3):e134-e40.

11. KESWA-Kenya. Silenced by law - the impact of the legal environment on health, safety, and protection in relation to sex work related violence in Kenya. Nairobi: KESWA-Kenya; 2018.

12. Hickey MD, Odeny TA, Petersen M, Neilands TB, Padian N, Ford N, et al. Specification of implementation interventions to address the cascade of HIV care and treatment in resourcelimited settings: a systematic review. Implement Sci. 2017;12(1):102. 
13. Punyam S, Pullikalu RS, Mishra RM, Sandri P, Mutupuru BP, Kokku SB, et al. Community advocacy groups as a means to address the social environment of female sex workers: a case study in Andhra Pradesh, India. J Epidemiol Commun Health. 2012;66(Suppl 2):ii87-94.

14. Beattie TS, Bhattacharjee P, Isac S, Mohan HL, Simic-Lawson M, Ramesh BM, et al. Declines in violence and police arrest among female sex workers in Karnataka state, south India, following a comprehensive HIV prevention programme. J Int AIDS Soc. 2015;18:20079.

15. Beattie TS, Bhattacharjee P, Ramesh BM, Gurnani V, Anthony J, Isac S, et al. Violence against female sex workers in Karnataka state, south India: impact on health, and reductions in violence following an intervention program. BMC Public Health. 2010;10:476.

16. Bhattacharjee P, Isac S, McClarty LM, Mohan HL, Maddur S, Jagannath SB, et al. Strategies for reducing police arrest in the context of an HIV prevention programme for female sex workers: evidence from structural interventions in Karnataka, South India. J Int AIDS Soc. 2016;19(4 Suppl 3):20856.

17. Bhattacharjee P, Morales GJ, Kilonzo TM, Dayton RL, Musundi RT, Mbole JM, et al. Can a national government implement a violence prevention and response strategy for key populations in a criminalized setting? A case study from Kenya. J Int AIDS Soc. 2018;21(Suppl 5):e25122.

18. Proctor E, Silmere H, Raghavan R, Hovmand P, Aarons G, Bunger A, et al. Outcomes for implementation research: conceptual distinctions, measurement challenges, and research agenda. Admin Pol Ment Health. 2011;38(2):65-76.

19. Ng M, Gakidou E, Levin-Rector A, Khera A, Murray CJ, Dandona L. Assessment of populationlevel effect of Avahan, an HIV-prevention initiative in India. Lancet. 2011;378(9803):1643-52.

20. Handley MA, Lyles CR, McCulloch C, Cattamanchi A. Selecting and improving quasiexperimental designs in effectiveness and implementation research. Annu Rev Public Health. 2018;39:5-25.

21. Collins AB, Boyd J, Hayashi K, Cooper HLF, Goldenberg S, McNeil R. Women's utilization of housing-based overdose prevention sites in Vancouver, Canada: an ethnographic study. Int J Drug Policy. 2020;76:102641.

22. Soekhai V, Whichello C, Levitan B, Veldwijk J, Pinto CA, Donkers B, et al. Methods for exploring and eliciting patient preferences in the medical product lifecycle: a literature review. Drug Discov Today. 2019;24(7):1324-31.

23. Shannon K, Crago AL, Baral SD, Bekker LG, Kerrigan D, Decker MR, et al. The global response and unmet actions for HIV and sex workers. Lancet. 2018;392(10148):698-710.

24. Platt L, Grenfell P, Meiksin R, Elmes J, Sherman SG, Sanders T, et al. Associations between sex work laws and sex workers' health: a systematic review and meta-analysis of quantitative and qualitative studies. PLoS Med. 2018;15(12):e1002680.

25. Bekker LG, Johnson L, Cowan F, Overs C, Besada D, Hillier S, et al. Combination HIV prevention for female sex workers: what is the evidence? Lancet. 2015;385(9962):72-87.

26. Argento E, Goldenberg S, Braschel M, Machat S, Strathdee SA, Shannon K. The impact of end-demand legislation on sex workers' access to health and sex worker-led services: a community-based prospective cohort study in Canada. PLoS One. 2020;15(4):e0225783.

27. Rojanapithayakorn W, Hanenberg R. The $100 \%$ condom program in Thailand. AIDS (London, England). 1996;10(1):1-7.

28. Kerrigan D, World Bank. The global HIV epidemics among sex workers. Washington, DC: World Bank; 2013. p. xxxvi, 305.

29. Awungafac G, Delvaux T, Vuylsteke B. Systematic review of sex work interventions in sub-Saharan Africa: examining combination prevention approaches. Trop Med Int Health. 2017;22(8):971-93.

30. Behanzin L, Diabate S, Minani I, Boily MC, Labbe AC, Ahoussinou C, et al. Decline in the prevalence of HIV and sexually transmitted infections among female sex workers in Benin over 15 years of targeted interventions. J Acquir Immune Defic Syndr. 2013;63(1):126-34. 
31. Alary M, Mukenge-Tshibaka L, Bernier F, Geraldo N, Lowndes CM, Meda H, et al. Decline in the prevalence of HIV and sexually transmitted diseases among female sex workers in Cotonou, Benin, 1993-1999. AIDS (London, England). 2002;16(3):463-70.

32. Ghys PD, Diallo MO, Ettiegne-Traore V, Satten GA, Anoma CK, Maurice C, et al. Effect of interventions to control sexually transmitted disease on the incidence of HIV infection in female sex workers. AIDS (London, England). 2001;15(11):1421-31.

33. Traore IT, Meda N, Hema NM, Ouedraogo D, Some F, Some R, et al. HIV prevention and care services for female sex workers: efficacy of a targeted community-based intervention in Burkina Faso. J Int AIDS Soc. 2015;18:20088.

34. Yadav G, Saskin R, Ngugi E, Kimani J, Keli F, Fonck K, et al. Associations of sexual risk taking among Kenyan female sex workers after enrollment in an HIV-1 prevention trial. J Acquir Immune Defic Syndr. 2005;38(3):329-34.

35. Kaul R, Kimani J, Nagelkerke NJ, Fonck K, Keli F, MacDonald KS, et al. Reduced HIV risk-taking and low HIV incidence after enrollment and risk-reduction counseling in a sexually transmitted disease prevention trial in Nairobi, Kenya. J Acquir Immune Defic Syndr. 2002;30(1):69-72.

36. Luchters S, Chersich MF, Rinyiru A, Barasa MS, King'ola N, Mandaliya K, et al. Impact of five years of peer-mediated interventions on sexual behavior and sexually transmitted infections among female sex workers in Mombasa, Kenya. BMC Public Health. 2008;8:143.

37. Feldblum PJ, Hatzell T, Van Damme K, Nasution M, Rasamindrakotroka A, Grey TW. Results of a randomised trial of male condom promotion among Madagascar sex workers. Sex Transm Infect. 2005;81(2):166-73.

38. Kerrigan D, Moreno L, Rosario S, Gomez B, Jerez H, Barrington C, et al. Environmentalstructural interventions to reduce HIV/STI risk among female sex workers in the Dominican Republic. Am J Public Health. 2006;96(1):120-5.

39. Lippman SA, Chinaglia M, Donini AA, Diaz J, Reingold A, Kerrigan DL. Findings from Encontros: a multilevel STI/HIV intervention to increase condom use, reduce STI, and change the social environment among sex workers in Brazil. Sex Transm Dis. 2012;39(3):209-16.

40. Pickles M, Boily MC, Vickerman P, Lowndes CM, Moses S, Blanchard JF, et al. Assessment of the population-level effectiveness of the Avahan HIV-prevention programme in South India: a preplanned, causal-pathway-based modelling analysis. Lancet Glob Health. 2013;1(5):e289-99.

41. Boily MC, Lowndes CM, Vickerman P, Kumaranayake L, Blanchard J, Moses S, et al. Evaluating large-scale HIV prevention interventions: study design for an integrated mathematical modelling approach. Sex Transm Infect. 2007;83(7):582-9.

42. Bertozzi SM, Padian N, Martz TE. Evaluation of HIV prevention programmes: the case of Avahan. Sex Transm Infect. 2010;86(Suppl 1):i4-5.

43. Kerrigan D, Kennedy CE, Morgan-Thomas R, Reza-Paul S, Mwangi P, Win KT, et al. A community empowerment approach to the HIV response among sex workers: effectiveness, challenges, and considerations for implementation and scale-up. Lancet (London, England). 2015;385(9963):172-85.

44. Goldenberg SM, Montaner J, Duff P, Nguyen P, Dobrer S, Guillemi S, et al. Structural barriers to antiretroviral therapy among sex workers living with HIV: findings of a longitudinal study in Vancouver, Canada. AIDS Behav. 2016;20(5):977-86.

45. Cowan FM, Chabata ST, Musemburi S, Fearon E, Davey C, Ndori-Mharadze T, et al. Strengthening the scale-up and uptake of effective interventions for sex workers for population impact in Zimbabwe. J Int AIDS Soc. 2019;22(Suppl 4):e25320.

46. Cowan FM, Davey C, Fearon E, Mushati P, Dirawo J, Chabata S, et al. Targeted combination prevention to support female sex workers in Zimbabwe accessing and adhering to antiretrovirals for treatment and prevention of HIV (SAPPH-IRe): a cluster-randomised trial. Lancet HIV. 2018;5(8):e417-e26. 
47. Lyons CE, Schwartz SR, Murray SM, Shannon K, Diouf D, Mothopeng T, et al. The role of sex work laws and stigmas in increasing HIV risks among sex workers. Nat Commun. 2020;11(1):773.

48. Chersich MF, Luchters S, Ntaganira I, Gerbase A, Lo YR, Scorgie F, et al. Priority interventions to reduce HIV transmission in sex work settings in sub-Saharan Africa and delivery of these services. J Int AIDS Soc. 2013;16:17980.

49. Ippoliti NB, Nanda G, Wilcher R. Meeting the reproductive health needs of female key populations affected by HIV in low- and middle-income countries: a review of the evidence. Stud Fam Plan. 2017;48(2):121-51.

50. Ferguson A, Shannon K, Butler J, Goldenberg SM. A comprehensive review of HIV/STI prevention and sexual and reproductive health services among sex workers in conflict-affected settings: call for an evidence- and rights-based approach in the humanitarian response. Confl Heal. 2017;11:25.

51. Dhana A, Luchters S, Moore L, Lafort Y, Roy A, Scorgie F, et al. Systematic review of facilitybased sexual and reproductive health services for female sex workers in Africa. Glob Health. 2014;10:46.

52. Petruney T, Minichiello SN, McDowell M, Wilcher R. Meeting the contraceptive needs of key populations affected by HIV in Asia: an unfinished agenda. AIDS Res Treat. 2012;2012:792649.

53. Yi S, Tuot S, Chhoun P, Brody C, Tith K, Oum S. The impact of a community-based HIV and sexual reproductive health program on sexual and healthcare-seeking behaviors of female entertainment workers in Cambodia. BMC Infect Dis. 2015;15:221.

54. Thyda L, Sineng S, Delvaux T, Srean C, Mary S, Vuochnea P, et al. Implementation and operational research: integration of family planning services in a peer-managed HIV care clinic serving most-at-risk populations in Phnom Penh, Cambodia. J Acquir Immune Defic Syndr. 2015;69(4):e120-6.

55. Feldblum PJ, Nasution MD, Hoke TH, Van Damme K, Turner AN, Gmach R, et al. Pregnancy among sex workers participating in a condom intervention trial highlights the need for dual protection. Contraception. 2007;76(2):105-10.

56. Lafort Y, Greener L, Lessitala F, Chabeda S, Greener R, Beksinska M, et al. Effect of a 'diagonal' intervention on uptake of HIV and reproductive health services by female sex workers in three sub-Saharan African cities. Trop Med Int Health. 2018;23(7):774-84.

57. Newman PA, Roberts KJ, Masongsong E, Wiley DJ. Anal cancer screening: barriers and facilitators among ethnically diverse gay, bisexual, transgender, and other men who have sex with men. J Gay Lesbian Soc Serv. 2008;20(4):328-53.

58. Quinn R, Salvatierra J, Solari V, Calderon M, Ton TG, Zunt JR. Human papillomavirus infection in men who have sex with men in Lima, Peru. AIDS Res Hum Retrovir. 2012;28(12):1734-8.

59. Vuylsteke B, Semde G, Sika L, Crucitti T, Ettiegne Traore V, Buve A, et al. High prevalence of HIV and sexually transmitted infections among male sex workers in Abidjan, Cote d'Ivoire: need for services tailored to their needs. Sex Transm Infect. 2012;88(4):288-93.

60. Wirtz AL, Peryshkina A, Mogilniy V, Beyrer C, Decker MR. Current and recent drug use intensifies sexual and structural HIV risk outcomes among female sex workers in the Russian Federation. Int J Drug Policy. 2015;26(8):755-63.

61. Decker MR, Lyons C, Billong SC, Njindam IM, Grosso A, Nunez GT, et al. Gender-based violence against female sex workers in Cameroon: prevalence and associations with sexual HIV risk and access to health services and justice. Sex Transm Infect. 2016;92(8):599-604.

62. Lyons CE, Grosso A, Drame FM, Ketende S, Diouf D, Ba I, et al. Physical and sexual violence affecting female sex workers in Abidjan, Cote d'Ivoire: prevalence, and the relationship with the work environment, HIV, and access to health services. J Acquir Immune Defic Syndr. 2017;75(1):9-17.

63. Arnott J, Crago A-L. Rights not rescue: a report on female, male, and trans sex workers' human rights in Botswana, Namibia, and South Africa. New York: Open Society Institute; 2009. 
64. Crago A-L. Our lives matter: sex workers unite for health and rights. New York: Open Society Institute; 2008.

65. Parcesepe AM, Engle KLL, Martin SL, Green S, Sinkele W, Suchindran C, et al. The impact of an alcohol harm reduction intervention on interpersonal violence and engagement in sex work among female sex workers in Mombasa, Kenya: results from a randomized controlled trial. Drug Alcohol Depend. 2016;161:21-8.

66. Decker MR, Tomko C, Wingo E, Sawyer A, Peitzmeier S, Glass N, et al. A brief, traumainformed intervention increases safety behavior and reduces HIV risk for drug-involved women who trade sex. BMC Public Health. 2017;18(1):75.

67. Tsai LC, Carlson CE, Aira T, Norcini Pala A, Riedel M, Witte SS. The impact of a microsavings intervention on reducing violence against women engaged in sex work: a randomized controlled study. BMC Int Health Hum Rights. 2016;16(1):27.

68. Yuen WW, Tran L, Wong CK, Holroyd E, Tang CS, Wong WC. Psychological health and HIV transmission among female sex workers: a systematic review and meta-analysis. AIDS Care. 2016;28(7):816-24.

69. Bozinoff N, Luo L, Dong H, Krusi A, DeBeck K. Street-involved youth engaged in sex work at increased risk of syringe sharing. AIDS Care. 2019;31(1):69-76.

70. Jeal N, Macleod J, Turner K, Salisbury C. Systematic review of interventions to reduce illicit drug use in female drug-dependent street sex workers. BMJ Open. 2015;5(11):e009238.

71. Strathdee SA, Abramovitz D, Lozada R, Martinez G, Rangel MG, Vera A, et al. Reductions in HIV/STI incidence and sharing of injection equipment among female sex workers who inject drugs: results from a randomized controlled trial. PLoS One. 2013;8(6):e65812.

72. Page K, Stein ES, Carrico AW, Evans JL, Sokunny M, Nil E, et al. Protocol of a cluster randomised stepped-wedge trial of behavioural interventions targeting amphetamine-type stimulant use and sexual risk among female entertainment and sex workers in Cambodia. BMJ Open. 2016;6(5):e010854.

73. Mergenova G, El-Bassel N, McCrimmon T, Terlikbayeva A, Primbetova S, Riedel M, et al. Project Nova: a combination HIV prevention and microfinance intervention for women who engage in sex work and use drugs in Kazakhstan. AIDS Behav. 2019;23(1):1-14.

74. Fung IC, Guinness L, Vickerman P, Watts C, Vannela G, Vadhvana J, et al. Modelling the impact and cost-effectiveness of the HIV intervention programme amongst commercial sex workers in Ahmedabad, Gujarat, India. BMC Public Health. 2007;7:195.

75. Burgos JL, Gaebler JA, Strathdee SA, Lozada R, Staines H, Patterson TL. Cost-effectiveness of an intervention to reduce HIV/STI incidence and promote condom use among female sex workers in the Mexico-US border region. PLoS One. 2010;5(6):e11413.

76. Kelly SL, Shattock AJ, Kerr CC, Stuart RM, Papoyan A, Grigoryan T, et al. Optimizing HIV/ AIDS resources in Armenia: increasing ART investment and examining HIV programmes for seasonal migrant labourers. J Int AIDS Soc. 2016;19(1):20772.

77. Mitchell KM, Prudden HJ, Washington R, Isac S, Rajaram SP, Foss AM, et al. Potential impact of pre-exposure prophylaxis for female sex workers and men who have sex with men in Bangalore, India: a mathematical modelling study. J Int AIDS Soc. 2016;19(1):20942.

78. Boily MC, Pickles M, Vickerman P, Buzdugan R, Isac S, Deering KN, et al. Using mathematical modelling to investigate the plausibility of attributing observed antenatal clinic declines to a female sex worker intervention in Karnataka state, India. AIDS (London, England). 2008;22(Suppl 5):S149-64.

79. Cianci F, Sweeney S, Konate I, Nagot N, Low A, Mayaud P, et al. The cost of providing combined prevention and treatment services, including ART, to female sex workers in Burkina Faso. PLoS One. 2014;9(6):e100107.

80. Wirtz AL, Pretorius C, Beyrer C, Baral S, Decker MR, Sherman SG, et al. Epidemic impacts of a community empowerment intervention for HIV prevention among female sex workers in generalized and concentrated epidemics. PLoS One. 2014;9(2):e88047. 
81. Decker MR, Wirtz AL, Pretorius C, Sherman SG, Sweat MD, Baral SD, et al. Estimating the impact of reducing violence against female sex workers on HIV epidemics in Kenya and Ukraine: a policy modeling exercise. Am J Reprod Immunol. 2013;69(Suppl 1):122-32.

82. UNAIDS. Miles to go-closing gaps, breaking barriers, righting injustices. Geneva: UNAIDS; 2018.

83. Fok CC, Henry D, Allen J. Research designs for intervention research with small samples II: stepped wedge and interrupted time-series designs. Prev Sci. 2015;16(7):967-77.

84. Wyman PA, Henry D, Knoblauch S, Brown CH. Designs for testing group-based interventions with limited numbers of social units: the dynamic wait-listed and regression point displacement designs. Prev Sci. 2015;16(7):956-66.

85. Baiocchi M, Cheng J, Small DS. Instrumental variable methods for causal inference. Stat Med. 2014;33(13):2297-340.

86. Gwadz MV, Collins LM, Cleland CM, Leonard NR, Wilton L, Gandhi M, et al. Using the multiphase optimization strategy (MOST) to optimize an HIV care continuum intervention for vulnerable populations: a study protocol. BMC Public Health. 2017;17(1):383.

Open Access This chapter is licensed under the terms of the Creative Commons Attribution 4.0 International License (http://creativecommons.org/licenses/by/4.0/), which permits use, sharing, adaptation, distribution and reproduction in any medium or format, as long as you give appropriate credit to the original author(s) and the source, provide a link to the Creative Commons license and indicate if changes were made.

The images or other third party material in this chapter are included in the chapter's Creative Commons license, unless indicated otherwise in a credit line to the material. If material is not included in the chapter's Creative Commons license and your intended use is not permitted by statutory regulation or exceeds the permitted use, you will need to obtain permission directly from the copyright holder.

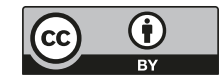

